IZA DP No. 5210

Returns to Education in Four Transition Countries: Quantile Regression Approach

Anita Staneva

G. Reza Arabsheibani

Philip Murphy

September 2010 


\title{
Returns to Education in Four Transition Countries: Quantile Regression Approach
}

\author{
Anita Staneva \\ Swansea University \\ G. Reza Arabsheibani \\ Swansea University \\ and IZA \\ Philip Murphy \\ Swansea University
Discussion Paper No. 5210
September 2010 \\ IZA \\ P.O. Box 7240 \\ 53072 Bonn \\ Germany \\ Phone: +49-228-3894-0 \\ Fax: +49-228-3894-180 \\ E-mail: iza@iza.org
}

Any opinions expressed here are those of the author(s) and not those of IZA. Research published in this series may include views on policy, but the institute itself takes no institutional policy positions.

The Institute for the Study of Labor (IZA) in Bonn is a local and virtual international research center and a place of communication between science, politics and business. IZA is an independent nonprofit organization supported by Deutsche Post Foundation. The center is associated with the University of Bonn and offers a stimulating research environment through its international network, workshops and conferences, data service, project support, research visits and doctoral program. IZA engages in (i) original and internationally competitive research in all fields of labor economics, (ii) development of policy concepts, and (iii) dissemination of research results and concepts to the interested public.

IZA Discussion Papers often represent preliminary work and are circulated to encourage discussion. Citation of such a paper should account for its provisional character. A revised version may be available directly from the author. 
IZA Discussion Paper No. 5210

September 2010

\section{ABSTRACT \\ Returns to Education in Four Transition Countries: Quantile Regression Approach}

This paper uses quantile regression techniques to analyze heterogeneous patterns of return to education across the conditional wage distribution in four transition countries. We correct for sample selection bias using a procedure suggested by Buchinsky (2001), which is based on a Newey $(1991,2009)$ power series expansion. We also examine the empirical implications of allowing for the endogeneity of schooling, using the control function approach proposed by Lee (2007). Using household data from Bulgaria, Russia, Kazakhstan and Serbia in 2003, we show that the return to education is heterogeneous across the earnings distribution. It is also found that accounting for the endogeneity of schooling leads to a higher rate of return to education.

JEL Classification: $\quad \mathrm{C} 14, \mathrm{I} 2, \mathrm{~J} 24$

Keywords: rate of return to education, endogeneity, sample selection, quantile regression

Corresponding author:

G. Reza Arabsheibani

School of Business and Economics

Swansea University

Richard Price Building

Singleton Park

Swansea, SA2 8PP

United Kingdom

E-mail: G.Arabsheibani@swan.ac.uk 


\section{Introduction}

Understanding the heterogeneous pattern of return to education across the conditional earnings distribution requires recognition of the affect that 'ability' and/or 'endogeneity' bias can have on the estimated returns. Human capital theory implicitly recognises that the return to education may be heterogeneous. Inter alia educational returns can vary across schooling levels and even across individuals with the same schooling level. Typically mean based regression models, like Ordinary Least Squares (OLS), fail to recognise this and so the estimated return from these models is unlikely to be an appropriate representation of the data. To place this idea into context we can envisage a process in which individuals are likely to differ with respect to not only the perceived benefits of education, but also the cost of education and the choices subsequently made in the labour market. In such circumstances the return to education is unlikely to be a single parameter; instead it is likely to vary systematically according to differences in individual's unmeasured characteristics, which in turn determine where in the overall earnings distribution an individual is placed. More generally any uncontrolled effect that is systematically correlated with an individual's position in the earnings distribution and which is also correlated with education attainment implies that the return to education is likely to vary across the earnings distribution. Accounting for this heterogeneity, therefore, requires an estimation strategy that allows the return to education to differ at different points in the earnings distribution.

An estimation procedure that allows the return to education to differ at different points in the earnings distribution is the quantile regression $(\mathrm{QR})$ model, and in this paper we use the QR model to address three important empirical questions. First, we examine the extent to which the return to education varies across the 
conditional earning distribution in four transition countries (Bulgaria, Russia, Kazakhstan and Serbia) in 2003. Second, we consider the impact sample selection bias has on the returns to education in the QR framework using Buchinsky's (1998, 2001) power series estimator ${ }^{1}$. Third, we investigate the empirical implications of allowing schooling to be endogenous (individual self-selection in the education process) in a QR context, using a control function approach proposed by Lee (2007).

The paper is organized as follows. In section 2, we briefly describe the education system in the selected transition countries. In section 3, the theory of quantile regression and endogeneity correction is presented, along with a brief discussion of Buchinsky's method for correcting for selectivity bias. In section 4, we comment on the data used in the estimation. Finally, sections 5 and 6 discuss the main results and conclusions.

\section{Education in transition to a Market Economy}

The education system and educational attainment is an essential feature of the transition process in Central and Eastern Europe and the Former Soviet Union. Typically the stock of human capital inherited by these countries from the socialist period was high by the standards of other countries at similar stages of their economic development. However, while the countries used in this study share a number of common influences, the paths of economic development followed by them differ in number of important respects, which makes for an interesting comparison of their earnings-education profiles.

There is a common perception in the literature to view Bulgaria and Serbia as Balkan countries in which the economic reforms following the break-up of the Soviet Union have progressed more slowly compared to the more advanced reform countries located in Central Europe. However, even within this simple classification interesting 
differences are still evident. For example, there are important differences between Serbia and Bulgaria both with respect to the speed of educational reforms and the impact these then had on labour market outcomes (Arandarenko, Kotzeva and Pauna 2006).

\section{Bulgaria}

Education in Bulgaria, although fundamentally national in character, has significant foreign influences. The Soviet influence was most evident during the period of the national revival in the nineteenth century and reflected the ideas of Slavophilism and pan-Orthodoxy. Education in Bulgaria is compulsory between the ages of 7 to 16. Prior to higher education the schooling system in Bulgaria consists of 12 school grades, organized in two major levels of study: basic and secondary. Basic education (grades one to eight) is divided into two sub-levels: elementary (grades one to four) and pre-secondary (grades five through eight). Secondary education normally encompasses grades eight to twelve and there are two major types of secondary schools: secondary comprehensive, usually called gymnasia (high school) and secondary vocational, most often referred to as tehnikum (vocational school).

\section{Russia}

Russia is an interesting case with transition from a planned economy to a market based economy that featured both over-education and over-employment,. The stages of compulsory schooling in Russia are: primary education for ages 6-7 to 9-10 inclusive; senior school for ages 10-11 to 12-13 inclusive, and senior school for ages 13-14 to 14-15 inclusive. If a secondary school pupil wishes to go on to higher education, he or she must stay at school for another two years. Primary and secondary schooling together account for 11 years of study, split into elementary (grades 1-4), middle (grades 5-9) and senior (grades 10-11) classes. 


\section{Kazakhstan}

As part of the Soviet Union, Kazakhstan achieved remarkably high attainment rates in education. During the Communist era education was a key priority and free compulsory schools were a feature of the Kazakhstan education system. The education system in Kazakhstan was highly responsive to the needs of a totalitarian regime and as a result was generously funded. Following independence, however, there was a dramatic drop in expenditure on education, which resulted in the closure of many facilities including pre-school nurseries that were highly dependent on state funding (Arabsheibani and Mussurov 2007).

Education in Kazakhstan starts at age 6 with pre-school preparation. Primary level starts at the age of 7 and continues for 3 years, with basic primary level extending to an additional 5 years at the basic secondary level. After successfully completing basic secondary level students proceed to general secondary (2 years) or to either vocational training (2-4 years) or Tehnikums (professional college). University level studies are divided between undergraduate and postgraduate levels with university degrees typically awarded after five years of study.

\section{Serbia}

Following the break-up of Yugoslavia and the problems it faced thereafter Serbia is today one of the poorest countries in Europe. The progress towards a stable democratic system in Serbia has been slow but amidst all of its problems Serbia has begun to rebuild and reform its education system. The link between poverty and education in Serbia is very strong, with $71 \%$ of the poor being without education or with only primary school education ${ }^{2}$. According to the last Census of population in $2002,3.45 \%$ of the population were illiterate and almost one million had not even completed primary schooling ${ }^{3}$. The education system in Serbia includes preschool, 
primary, secondary, higher, and university education. Preschool covers children from 6 to 7 years old. Primary education lasts eight years, and it is the only compulsory part of education system in Serbia. Secondary education follows primary education and while it is not compulsory it is free for all. Secondary schools are divided into gymnasiums and vocational schools, each of which lasts 3 or 4 years. Considerable reforms in the field of higher education have taken place in Serbia since it became a signature of the Bologna declaration in September 2003.

\section{Econometric methodology}

\section{Quantile regression approach}

Our distributional approach is based on the use of Quantile Regression $(\mathrm{QR})$ (Koenker and Bassett 1978), which provides estimates of the effect of education on earnings at different points of the earnings distribution. Estimating the effect of education at conditional quantiles, therefore, allows for heterogeneity in the returns to education. Just as least square models the conditional mean of the dependent variable $Y$ relative to the covariates $X$ used in the analysis, quantile egressions give estimates of the effect of covariates at different percentiles of the conditional distribution ${ }^{4}$.

In a wage equation setting, the quantile regression model can be written as:

$$
\ln Y_{\theta i}=X_{i} \beta_{\theta}+u_{\theta i} \text { with } Q_{\theta}\left(\ln Y_{i} \mid X_{i}\right)=\beta_{\theta} X_{i}
$$

where $Q_{\theta}\left(\ln Y_{i} \mid X_{i}\right)$ denotes the conditional quantile $\theta$ of $\ln Y_{i}$, conditional on the regressor vector $X_{i}$.

Estimates at different quantiles can be interpreted as showing the response of the dependent variable to the regressors at different points in the conditional wage distribution. The relative positioning of workers in the conditional wage distribution, therefore, can be related to systematic differences in unobservables, which generically 
may be referred to as 'ability' and include a diverse range of attributes like motivation, labour market connections, family human capital, school quality, etc (Arias, Hallock and Escudero 2001).

\section{Sample selection in quantile regression framework}

There is an additional complication that is not accounted for in the description of the QR given above, namely pre-selection into employment. Specifically working women and men may not be a randomly selected sample from the overall population, which can lead to biased estimates of the earnings equation ${ }^{5}$. Methods for correcting selectivity bias in quantile regression models have only recently been developed. The bivariate normality assumption typically made in the OLS model between the error terms in the earnings and participation equation will not necessarily hold in the quantile regression case. Buchinsky (1998) suggests an approach using the nonparametric procedure of Newey (1991) to deal with this problem, and in this application the presence of children in the household is used as the identifying restriction in the participation equation. The estimation procedure followed can be briefly described as follows. First, an estimate of the latent index determining labour market participation is found from a standard Probit model. Estimates of the latent index from this model are then used as an argument in a power series expansion, which is designed to approximate the unknown quantile functions of the truncated bivariate distribution of the error terms in the wage and participation equations.

To perform the semi-parametric correction procedure we define the participation equation as ${ }^{6}$ :

$$
g_{i}=\gamma Z_{i}+u_{i}
$$

where $g_{i}$ is an index function. 
To get unbiased estimates of $\beta_{\theta}$ for the male and female respondents it is necessary to introduce an extra term:

$$
\ln Y_{\theta i}=\beta_{\theta} X_{i}+h_{\theta}\left(g_{i}\right)+\xi_{\theta i}
$$

where:

$$
h_{\theta}\left(g_{i}\right)=\operatorname{Quant}_{\theta}\left(\xi_{\theta i} \mid Z_{i}, g_{i}>0\right)
$$

The term $h_{\theta}\left(g_{i}\right)$ includes information about the unobservables that affect individual labour force participation decisions. The estimated probability function provides the location for the index $\hat{g}\left(\hat{\gamma} Z_{i}\right)$ and the values of $\hat{g}=\hat{\gamma} Z_{i}$ are used to expand $h_{\theta}\left(g_{i}\right)$ in a power series by approximating:

$$
\hat{g}\left(\gamma Z_{i}\right)=\sum_{k=1}^{k} \alpha^{k}\left(\hat{g}_{i}\right)^{k-1}
$$

where $k$ is the number of terms in the approximating series, which is allowed to grow with the sample size. In the results reported experimentation with different power series indicated that a second order power series was sufficient in each case ${ }^{7}$.

\section{Endogeneity in the quantile regression model}

In many empirical regression models, it is common to have a regressor that is endogeneous $^{8}$. If the return to schooling is endogenous estimates of the returns to education from a standard QR model may be misleading. To control for endogeneity bias in a quantile regression framework, we adopt the control function approach proposed by Lee (2007). As an alternative to existing methods in the literature, Lee's methodology extends the control function approach to the structural quantile regression model semi-parametrically. He shows that under suitable conditions, the estimator obtained from the control function approach is consistent and asymptotically normally distributed. 
Formally Lee (2007) considers the following model, which is a semiparametric quantile regression version of Newey, Powell and Vella (1999):

$$
\begin{aligned}
& Y=X \beta(\tau)+Z_{1}^{\prime} \gamma(\tau)+U \\
& X=\mu(\alpha)+Z^{\prime} \pi(\alpha)+V
\end{aligned}
$$

where $Y$ is the dependent variable, $X$ is real-valued continuously distributed endogenous explanatory variable, $Z \equiv\left(Z_{1}, Z_{2}\right)$ is a $\left(d_{z} \times 1\right)$ vector of exogenous explanatory variables, $U$ and $V$ are real-valued unobserved random variables, $\beta(\tau)$ and $\gamma(\tau)$ are unknown structural parameter of interest, $\mu(\alpha)$ is an unknown parameter, $\pi(\alpha) \equiv\left[\pi_{1}(\alpha), \pi_{2}(\alpha)\right]$ vector is a $\left(d_{z} \times 1\right)$ vector of unknown parameters for some $\tau$ and $\alpha$ such that $0<\tau<1$ and $0<\alpha<1$. For identification it is assumed that there is at least one component of $Z$ that is not included in $Z_{1}$, and that there is at least one non-zero coefficient for the excluded components of $Z$. That is, $d_{z 1}<d_{z}$ and $\pi_{2}(\alpha) \neq 0$, where $d_{z 1}$ is the dimension of $Z_{1}$.

In our return to education estimates, the reduced- form schooling residuals $V$ are interpreted as 'individual ability' and therefore $U$ is not assumed to be independent of $V$. The approach corrects for endogeneity by adding residual power series estimates as additional explanatory variables and is interpreted as a variant of control function approach ${ }^{9}$ (e.g., Newey, Powell and Vella 1999; Blundell and Powell 2003b).

Following the method proposed by Trostel, Walker and Woolley (2002), we use spouse's education as an instrument. The instrument should be correlated with the partner's education while uncorrelated with the error term in the earnings equation. Assortative mating can be invoked to ensure there is a correlation between partners education, either as a result of household specialisation or as a result of partners sharing common interests and that that lead to them having similar levels of schooling 
(Pencavel 1998). As Trostel et al. (2002) point out, however, assuming no association between 'spouse's' education and the error term in the partners earnings equation is potentially more problematic, particularly if the level of schooling of both partners are complements in the production of household income. Because Trostel et al had more than one potential instrument to use in their analysis they were able to undertake a Sargan instrument validity test to provide support for their empirical approach. Unfortunately in most of the countries dealt with in this paper we only have one identifying instrument and are, therefore, unable to undertake a similar test. However, in the case of Kazakhastan we have access to the same instruments used in the Trostel et al paper (spouses and mothers education). In this case a Sargan instrument validity test was passed for both male and female samples, which we feel provides some support for the approach adopted here.

\section{The Data}

We use data from the Bulgarian Multi-Topic Household Survey (2003), the Russian NOBUS Survey (2003), the Kazakhstan Household Budget Survey (2003) and Serbian Living Standard Measurement Survey (2003) in the analysis reported below.

The Bulgarian Multi-Topic Household Survey, which was carried out in October and November 2003, includes information on income, expenditures, demographic and labour market characteristics for a representative sample of 3,023 Bulgarian households. The subset of the data used in the estimation consists of a sample of 1,296 men and 1,186 women. Table 1 reports summary statistic for the sample of working men and women. The descriptive statistics indicate that average $\log$ hourly wage rate for men in Bulgaria is higher for men than it is for women. Moreover, women have more years of schooling than men, reflecting the fact that 
women that work in Bulgaria are more likely to have participated in higher education than men. Thus, while $62 \%$ of employed men and $53 \%$ of employed women in Bulgaria have secondary schooling, $26 \%$ of working women have a university degree compare to only $17 \%$ of men.

The Russian NOBUS dataset provides detailed information on household consumption and income; together with information on household demographics, labour market participation, access to health, education and social programs, and subjective perceptions of household welfare. Summary statistics for the Russian working sample are presented in Table 2, and consists of 21,874 men and 24,318 women. There are considerable differences in the characteristics of men and women with respect to both educational qualifications and occupational status. The data indicates that women earn less than men, with a raw gender wage gap of about $26 \%$. We can see that a higher proportion of women than men have completed a university degrees (24\% and $18 \%$ respectively), while a significantly higher proportion of working men are married (76\%) compared to women who are much more likely to have been divorced. This suggests that the labour market participation of women in Russia is significantly affected by their marital status and by the need of divorced women to work following the break-up of their marriages. Not surprisingly, women's employment is more concentrated than men's in the public sector $(69 \%$ of female employment is in the public sector compared to only $60 \%$ of male employment), and as a result women are less represented in the private sector where both job opportunities and employment flexibility are less likely to as attractive to workers.

The Kazakhstan data (KHBS) was collected by the Kazakhstan Agency of Statistics with technical assistance from the World Bank. The survey covers household income and employment, health and education attainment. The sample is 
randomly selected and based on a register of household dwelling in Kazakhstan. After excluding students, children who are less than 16 years of age, and pensioners the sample consist of 16,375 individuals, of whom 7,868 are male and 8,507 are female. Table 3 reports the main descriptive statistics. The Kazakhstan sample does not provide a direct measure of the years of individual schooling, instead respondents are asked about their highest level of education attainment. The schooling variable used in the analysis, therefore, is constructed in the following way: if no qualification or nursery education is indicated $S=1$, if primary $S=3$, if general secondary $S=8$, if high school $S=10$, if vocational technical school $S=10$, if college $S=12$, if degree $S=15$ and if postgraduate $S=20$ (see Arabsheibani and Mussurov 2006). The dependent variable in the analysis is earnings reported after taxes. Unfortunately, unlike the other surveys used in this paper, the Kazakhstan survey did not ask about the number of hours worked by individuals, as a result monthly income is taken as the measure of earnings for Kazakhstan. Specifically, the dependent variable used in the analysis is the log of monthly earnings received from the main job, and excludes earnings from secondary jobs, or from agricultural production, and non-monetary benefits.

The descriptive statistics for Kazakhstan reported in Table 3 show that as in the other transition countries women earn less than men. Women are also more likely to be employed in the public sector and have more years of schooling. The percentage of working women in Kazakhstan that have a university degree is $24 \%$ compared to only $17 \%$ for men.

Finally to estimate the return to education in Serbia, we use Serbian Living Standard Measurement Survey (2003). The Labour Market module in this survey is similar to the Labour Force Survey (LFS), but with additional questions to capture informal sector activities that provide more detailed information on earnings. The 
sample used in the analysis consists of 2,548 households of which 2,450 individuals have information on hourly earnings. Table 4 reports the main descriptive statistics. The average log hourly wage rate is higher for men than for women, and $11.4 \%$ of employed women in Serbia have obtained a university degree compared to only $7.7 \%$ of men.

\section{Empirical Results}

The QR models estimated in this paper are based on an augmented Mincer (1974) earnings equation, with the natural logarithm of earnings regressed on an individual's completed years of schooling and potential labour market experience (and its square). Additional controls for marital status, job-tenure, region of work, ethnicity, public sector employment, health, and managerial responsibilities are also included in the analysis. The Russian specifications is also supplemented with series of variables that capturing part-time employment and wage arrears effects ${ }^{10}$.

\section{Bulgaria}

We first estimate the Bulgarian earning function assuming schooling is exogenous. Tables 5 and 6 report the QR estimates for five values of $\theta\left(10^{\text {th }}, 25^{\text {th }}\right.$, $50^{\text {th }}, 75^{\text {th }}$ and $90^{\text {th }}$ percentiles) for Bulgarian males and females respectively. The estimated returns to schooling are also plotted for each percentile in Figure 1, along with the $95 \%$ confidence interval for each point estimate. Superimposed on the plot, in Figure 1, is a dashed line representing the OLS estimate of the effect of education on hourly earnings. Each side of the OLS estimate is a dotted line which shows the associated $95 \%$ confidence interval of the estimate.

Figure 1 about here

Table 5 about here

Table 6 about here 
The effect of education on wages is positive and statistically different from zero at each of the reported percentiles. This indicates hourly earnings in Bulgaria increase with education throughout the conditional wage distribution. Moreover, the horizontal line in Figure 1, which plots the OLS estimate and its 95\% confidence interval, indicates that the estimated mean return to schooling is not representative of the effect education has on earnings at all points in the earnings distribution. Instead the return to schooling is higher at higher points in the earnings distribution. For instance, the return to schooling for males in Bulgaria increases from $3.9 \%$ to $6.0 \%$ between the $10^{\text {th }}$ and $90^{\text {th }}$ percentile and from $4.9 \%$ to $7.4 \%$ for females (See Table 5 and Table 6$)^{11}$. In this case, therefore, schooling has a positive impact upon wage inequality in Bulgaria. Arias, Hallock and Escudero (2001) have interpreted a positive ability-returns relationship as evidence that education and ability are complements in the human capital generation process, which if true suggests that more able individuals in Bulgaria benefit most from educational investment. However, there might be other explanations for this pattern. Because personal abilities and skills (cognitive and non-cognitive) are unobserved by economists, it is difficult to isolate the effect that drives the heterogeneous pattern of returns to education across the wage distribution. For example, workers with identical education do not necessarily have to have the same level of productivity because of the influence of unobserved variables that are systematically correlated with both measured education and an individual's place in the earnings distribution.

More generally the Bulgarian results reported here are consistent with previous estimates reported in the literature. Martins and Pereira (2004) and Flabbi, Paternostro and Tiongson (2008), for example, both report higher returns to education at the top end of the conditional wage distribution. 
Following Vella (1998), we estimate the latent index $\hat{g}\left(\hat{\gamma} Z_{i}\right)$ that determines male and female labour market participation parametrically using a probit model. A range of familiar variables are used as covariates in the participation equation, including the presence of dependent children in the household which is used to identify the participation on the assumption that this variable is exogenous ${ }^{12}$. An estimate of the latent index from the participation equation is then used in a power series to obtain estimates of the selectivity adjusted QR model. Selection corrected estimates for Bulgaria indicate that the power series correction terms included in the QR analysis were not significant for either males or females workers. We can conclude, therefore, that sample selection effects are not an issue for the estimation of male and female earnings equations in Bulgaria (Table 5 and Table 6).

We adjust for endogeneity bias by using the Lee's (2007) control function approach. A fifth order polynomial of the reduced form residuals is used in the analysis to estimate the return to schooling at different values of $\theta^{13}$. Spouse's education is used as an instrument, and there is a significant and positive relationship between this variable and the partner's level of schooling ${ }^{14}$. A Durbin-Hausman Wu test (DWH) (Davidson and McKinnon 1993) is used to test the hypothesis of endogeneity of schooling ${ }^{15}$. The results are not sensitive to the choice of the order of the residual polynomial used in the analysis. In the male specification (Table 5) there is no statistical difference between unadjusted QR return to education and the return to education adjusted for endogeneity using the control function approach. This finding is supported by the insignificance of the power terms included in the male equation and by the DWH test that fails to reject the null that schooling is exogenous. We can conclude, therefore, that male schooling is exogenous and accept the unadjusted QR estimates being consistent estimates of the returns to schooling. On the 
other hand, the DWH test undertaken on the female earnings equation leads to a strong rejection of the null hypothesis of exogeneity of schooling and the endogeneity adjusted QR results for females are quite different from the unadjusted QR results. In particular the endogeneity adjusted female $Q R$ results show a much more heterogeneous pattern of return to education as we move across the earnings distribution (Table 6). Specifically correcting for the endogeneity of schooling increases the return to schooling at each point in the earnings distribution for females in Bulgaria, but the effect is much more pronounced at the top end of the distribution.

\section{Russia}

Figure 2 shows the estimated returns to education for Russian males and females at different percentiles, assuming schooling to be exogenous. Both male and female results show that return to schooling is higher in the lower part of the earnings distribution than at the top end of the distribution. For instance, the returns to education for males fall from $9.3 \%$ to $5.9 \%$ between the $10^{\text {th }}$ and $90^{\text {th }}$ quantile (Table 7) and for females the equivalent fall is from $8.9 \%$ to $6.6 \%$ (Table 8). Moreover these differences are significant as an $F$-test decisively rejects the equality of the estimates at the $10^{\text {th }}$ and $90^{\text {th }}$ percentiles for both male and female workers in Russia.

Figure 2 about here

Table 7 about here

Table 8 about here

Mwabu and Schultz (1996) and Arias, Hallock and Escudero (2001) interpret a negative ability-returns relationship as evidence of education and ability being substitutes, which implies that maximising the returns to education may require increasing educational opportunities for less able individuals in Russia. Flabbi Paternostro and Tiongson (2008) also find evidence for a higher return to education in 
the lower part of the earnings distribution in Russian in the early (1991-1996) and late transition (1997-2002) periods. Similarly Gorodnichenko and Sabirianova (2005) find that the university wage premium in Russia is higher in the lower part of the earnings distribution than in top part of the earnings distribution.

There are, however, a number of alternative explanations for this pattern. First, a demand-side effect could drive down the return to education at different points in earnings distribution because of an oversupply of well-educated workers in the economy (the supply effect dominates the demand effect at higher points in the earnings distribution). Second, a negative relationship between 'ability' and the return to schooling could also reflect differences in the educational attainment of the labour force (Herrnstein and Murray 1994). Similarly, lower returns to education at the higher end of the earnings distribution suggests there are factors leading to highpaying employment that act independently of education-generating human capital process. It is also possible to interpret the results in terms of a "state" or "foreign" ownership effect. State ownership is much more relevant to the lower tail of the wage distribution and relatively low paid workers earn more in stated owned firms. However, this state ownership effect tends to die away as there is movement up through the earnings distribution (Machado and Mata 2001).

A comparison of unadjusted QR estimates and those corrected for sample selectivity suggests that the return to education in Russia is sensitive to this correction (Tables 7 and 8). The selection corrected male education return is slightly higher compared to that when selection is ignored and the difference tends to be higher at the bottom of the distribution than at the top. By way of contrast the female selectivity corrected estimates indicate that the return to schooling is lower in the unadjusted QR results at all points in the earnings distribution. 
Endogeneity adjusted QR estimates for males reported in Table 7 indicate that apart from the $90^{\text {th }}$ percentile, where the return to education is insignificant and negative, the effect of correcting for the endogeneity of schooling has little affect on the estimates return to schooling at other percentile levels. This finding is supported to some extent by the DWH test, which fails to reject the null that schooling is exogenous. However, endogeneity adjusted returns to schooling are quite different for females in Russia, where the effect of adjusting for endogeneity of schooling typically increases the adjusted returns to education. Moreover, this effect tends to be more pronounced in the top end of the distribution than in the bottom end of the distribution.

\section{Kazakhstan}

The Kazakhstan QR estimates are presented in Tables 9 and 10. The returns to education at different percentiles are also shown in Figure 3. OLS returns differ significantly from QR returns and as in other countries reported in this paper the QR estimates are all positive and significantly different from zero. Tables 9 and 10 indicate that the estimated return to education in Kazakhstan for both males and females are lowest in the bottom end of the earnings distribution and tend to increase as we move up through the distribution. Interestingly the returns to education for females tend to increase more rapidly than the corresponding return for men, suggesting that inequality is more pronounced for females than men in terms educational returns. At the highest percentile $\left(90^{\text {th }}\right)$ the return to schooling is $6.4 \%$ for females and $4.8 \%$ for males, while the equivalent comparison at the $10^{\text {th }}$ percentile is a return of $1.2 \%$ for females and $2.4 \%$ for males. A test of whether the estimated returns to education differ across each of these percentile levels indicates that there is significant difference in the returns for both male and female workers in Kazakhstan. 
Evidence of sample selectivity effects for males in Kazakhstan is provided by the significance of the second order term in the series approximation. Correcting for selection has a dramatic effect on the returns to schooling for males in this sample, reducing the return to a level which is not significantly different from zero at all percentiles (Table 9). If true this finding would suggest that for males in Kazakhstan education is important for determining participating in the labour force but thereafter has little effect on the earnings of individuals. The coefficients on both selection terms in the female earnings equation are significant at all percentile levels. However, while correcting for participation into work results in reduction in the female return to education at most percentiles, the difference between the adjusted and unadjusted QR estimates is not statistically significant.

Figure 3 about here

Table 9 about here

Table 10 about here

An examination of the results in Tables 9 and 10 suggests that the effects of adjusting for the endogeneity of schooling is most marked at the top end of the earnings distribution for both male and female workers in Kazakhstan. Endogeneity corrected returns to education are typically higher in the top end of the distribution than those reported for the unadjusted results. The same pattern is also evident for males and females at the $10^{\text {th }}$ percentile, but at intervening points in the earnings distribution the difference between the unadjusted QR estimates and those corrected for endogeneity are much less marked.

\section{Serbia}

The Serbian QR results are reported in Tables 11 and 12. Figure 4 also plots the unadjusted QR estimates of the return to education across different points in the 
earnings distribution, assuming schooling is exogenous. The unadjusted QR estimates indicate that return to education for Serbian men and women are positive and statistically significant at all points in the earnings distribution. However, the QR estimates do not deviate markedly from the OLS estimates, and the confidence intervals for these two sets of estimates tend to overlap at most points in the earnings distribution. For Serbian men the return to education across the earnings distribution is quite flat and there is not statistically significant difference between the returns at the $90^{\text {th }}$ and $10^{\text {th }}$ percentiles $(F$-statistics $p$-value $=0.12)$. The return to education for Serbian females is much less uniform. For example, the unadjusted QR estimates suggest that the return to education for Serbian women is higher at the top of the earnings distribution than at the bottom and these differences are statistically significant. In Serbia therefore, education leads to more variation in the earnings of women than it does for men.

Figure 4 about here

Table 11 about here

Table 12 about here

In Serbia there is little compelling evidence of strong sample selection effects. Selectivity terms in the series estimator are invariably insignificant at conventional levels of significance. However, endogeneity corrected returns to schooling are quite different from the unadjusted $\mathrm{QR}$ estimates for both male and female workers. Moreover, this effect is particularly pronounced at the lowest percentiles where we find significantly lower estimated returns to education when account is made for the endogeneity of schooling. Interestingly, however, in this case a DWH test of the exogeneity of schooling suggests that endogeneity is only an issue in the female specification. 


\section{Conclusion}

In summary, the empirical evidence suggests that the return to education varies as we move across the earnings distribution. There is a tendency for returns to increase monotonically and to remain higher in the upper tail of the distribution in Bulgaria and Kazakhstan. We interpret these increasing returns as an indication that 'ability', when broadly defined, and education complement each other. The reason for heterogeneity in the returns to education is likely to be due to the fact that differences in 'ability' translate into higher pay differentials between high-ability and low-ability workers. Explaining the negative relationship in Russia, however, requires further investigation.

A comparison of unadjusted $\mathrm{QR}$ estimates and estimates corrected for selectivity suggests that estimates of the returns to education are sensitive to a correction for sample selection. Sample selection results indicate lower return to education for females in both Russia and Kazakhstan.

We also consider the issue of endogeneity in the education-earning relationship by treating educational attainment as an endogenous variable. We find that the endogeneity of schooling is primarily an issue among the female samples used in the analysis. Typically endogeneity adjusted estimates of the returns to education tend to be higher compared to the returns found from unadjusted QR estimates. We conclude, therefore, that failure to account for the endogeneity of schooling seems creates a slight downward bias in the estimated returns to education for females. However, even when the endogeneity of schooling is taken into account there remains significant heterogeneity in the returns to education across the earnings distribution in most of these transition countries. 


\section{Notes}

1. Buchinsky (2001) applies the sample selection model in a quantile regression framework to estimate women's return to education in the U.S. He shows that the semi-parametric estimates of the sample selection equation are considerably different from those obtained for a parametric Probit model and that there is significant sample selection bias for all age groups and quantiles.

2. UNICEF Serbian Annual Report, 2007.

3. The population in Serbia was 7.5 million in 2002, excluding Kosovo.

4. Another advantage of quantile regression is that it tends to be less sensitive to the presence of outliers in the dependent variable. This is because in quantile regression the residuals to be minimized are not squared as in OLS, and as a result outliers receive less emphasis. Moreover, if the error term of the regression is not distributed normally, QR may be more efficient than mean regression (Buchinsky 1998).

5. Most papers disregard this problem for males arguing that because nonparticipation among males is low an econometric framework based on a bivariate selection equation is likely to be unstable.

6. We follow Buchinsky (1998) modification and assume that the error term does not take on a specific parametric form.

7. According to Buchinsky (1998) addition of more terms can result in severe multicollinearity problems.

8. Endogeneity may arise when a regressor and the dependent variable are determined simultaneously or when the regressor is a consequence of self-selection. Both of these features may apply in the case of education.

9. This two-step estimator closely resembles the approach of Buchinsky (1998) in which sample selection is corrected for nonparametrically by a two-stage procedure. The procedure imposes no functional form restrictions on the stochastic relationship between the reduced-form residuals and the disturbance term in the primary equation, conditional on observable covariates. The residuals can capture the effect of unobserved variables, which might otherwise affect individual productivity and earnings.

10. Wage arrears or unprecedented delays in the payment of wages have become an endemic feature of the Russian labour market. There are several forms wage arrears can take in Russia: 1) not paid wages 2) delayed but paid in full wages, 3) paid in time but not in full or 4) paid in part and not in time wages. 11. There is statistically significant difference between the return to education at the $10^{\text {th }}$ and $90^{\text {th }}$ percentiles for both males and females in Bulgaria (the $F$ statistic for males is 4.16, $p$-value $=0.000$; and the $F$ statistic for females is $4.07, p$-value $=0.000$ ).

12. A commonly made assumption in the literature is that fertility decisions are exogenous to decisions about labour force participation. The full set of probit results are available from the authors on request.

13. Lee (2007) provides a condition which restricts the growth rate of the power series k. The necessary smoothness condition is that $r \geq 5$.

14. The successful use of instrumental variable estimator rests on the validity and quality of instruments used. If we regress education on the control variables and the instrument, the $F$-statistic on the excluded instrument in the male equation is 12.26 and in the female equation it is 347.42 . Stock, Wright and Yogo (2002) suggest that $F$-statistics above 10 put is in the save zone.

15. The DWH test was conducted on a standard conditional mean regression model as no equivalent test exists for the QR model. 


\section{References}

Arabsheibani, G. Reza, and A. Mussurov. 2007. Returns to schooling in Kazakhstan: OLS and instrumental variables approach. Economics of Transition 15(2): 341-364.

Arandarenko, M., M. Kotzeva, and B. Pauna. 2006. Valuing Human capital in Balkan Transition countries.

Arias, O., K. Hallock, and W. Sosa-Escudero. 2001. Individual heterogeneity in the returns to schooling: instrumental variables quantile regression using twins data. Empirical Economics 26(1): 7-40.

Blundell, R., and J. Powell. 2003b. Endogeneity in nonparametric and semiparametric regression models. Review of Economic Studies, forthcoming

Buchinsky, M. 1994. Changes in the US wage structure 1963-1987: Application of quantile regression. Econometrica: 405-458.

Buchinsky, M. 1995. Estimating the asymptotic covariance matrix for quantile regression models. A Monte Carlo study. Journal of Econometrics 68(2): 303338.

Buchinsky, M. 1998. The dynamics of changes in the female wage distribution in the USA: a quantile regression approach. Journal of Applied Econometrics 13(1): $1-30$.

Buchinsky, M. 2001. Quantile regression with sample selection: Estimating women's return to education in the US. Empirical Economics 26(1): 87-113.

Davidson, R., and J. MacKinnon. 1993. Estimation and inference in econometrics. New York : Oxford University Press.

Denny, K., and V. O'Sullivan. 2007. Can education compensate for low ability? Evidence from British data. Applied Economics Letters 14 (7-9): 657-660.

Eren, O. 2009. Ability, Schooling Inputs and Earnings: Evidence from the NELS. Canadian Economic Association Meetings at University of British Columbia June, 2008.

Flabbi, L., S. Paternostro, and E. Tiongson. 2008. Returns to education in the economic transition: A systematic assessment using comparable data. Economics of Education Review 27(6): 724-740.

Gorodnichenko, Y., and K. Sabirianova. 2005. Returns to schooling in Russia and Ukraine: A semiparametric approach to cross-country comparative analysis. Journal of Comparative Economics 33(2): 324-350.

Herrnstein, R., and C. Murray. 1994. The bell curve: Intelligence and class structure in American life. New York.

Koenker, R., and G. Bassett. 1978. Regression quantiles. Econometrica 46(1): 33-50.

Lee, S. 2007. Endogeneity in quantile regression models: A control function approach. Journal of Econometrics 141(2): 1131-1158.

Machado, J., and J. Mata. 2001. Earning functions in Portugal 1982-1994: Evidence from quantile regressions. Empirical Economics 26 (1): 115-134.

Martins, P., and P. Pereira. 2004. Does education reduce wage inequality? Quantile regression evidence from 16 countries. Labour Economics 11(3): 355-371.

Melly, B. 2006. Public and private sector wage distributions controlling for endogenous sector choice. Swiss Institute for International Economics and Applied Economic Research. Mimeo.

Mincer, J. 1974. Schooling, experience, and earnings. Columbia University Press, New York. 
Mwabu, G., and T. Schultz. 1996. Education returns across quantiles of the wage function: alternative explanations for returns to education by race in South Africa. The American Economic Review 86 (2): 335-339.

Newey, W. 1988. Adaptive estimation of regression models via moment restrictions. Journal of Econometrics 38 (3): 301-339.

Newey, W. 1991. Two-step series estimation of sample selection model. Mimeo, Department of Economics, Massachusetts Institute of Technology.

Newey, W. 2009. Two-step series estimation of sample selection models. Econometrics Journal 12(s1): S217-S229.

Newey, W., J. Powell, and F. Vella. 1999. Nonparametric estimation of triangular simultaneous equations models. Econometrica: 565-603.

Pencavel, J. 1998. Assortative mating by schooling and the work behavior of wives and husbands. The American Economic Review 88(2): 326-329.

Powell, J. 1986. Censored regression quantiles. Journal of Econometrics 32(1): 143155.

Slavkovic, G., and K. Eisuke. 2009. Adaptation of Serbian University to Bologna Process. Nagoya Higher Education. 9: 257-276

Stock, J., J. Wright, and M. Yogo. 2002. A survey of weak instruments and weak identification in generalized method of moments. Journal of Business and Economic Statistics 20 (4): 518-529.

Trostel, P., I. Walker, and P. Woolley. 2002. Estimates of the economic return to schooling for 28 countries. Labour Economics 9 (1): 1-16.

UNICEF. 2007. Serbian Annual report.

Vella, F. 1998. Estimating models with sample selection bias: a survey. The Journal of Human Resources 33 (1): 127-169.

Welch, F. 1979. Effects of cohort size on earnings: the baby boom babies financial bust. Journal of Political Economy 87: S65-S97.

Word Bank. 1995. World Development Report. 
Table 1. Descriptive statistics- Bulgaria, LSMS 2003

\begin{tabular}{|c|c|c|c|c|c|}
\hline \multicolumn{2}{|c|}{ Bulgaria 2003} & \multicolumn{2}{|c|}{ Males } & \multicolumn{2}{|c|}{ Females } \\
\hline Variable & Description & Mean & Std. Dev. & Mean & Std. Dev. \\
\hline lhwage & Log of hourly wage & 1.622 & 0.558 & 1.460 & 0.519 \\
\hline $\exp$ & Potential experience & 19.972 & 12.264 & 18.653 & 11.179 \\
\hline expsq & Potential experience squared & 549.182 & 558.242 & 472.788 & 457.067 \\
\hline hours & Hours worked per week & 42.360 & 8.436 & 41.006 & 6.511 \\
\hline married & $=1$ if married & 0.680 & 0.467 & 0.728 & 0.445 \\
\hline tenure 1 & $=1$ if $<7$ months & 0.164 & 0.370 & 0.121 & 0.326 \\
\hline tenure 2 & $=1$ if $7-12$ months & 0.106 & 0.309 & 0.105 & 0.307 \\
\hline tenure 3 & $=1$ if $1-2$ years experience & 0.177 & 0.382 & 0.163 & 0.369 \\
\hline tenure 4 & $=1$ if $3-5$ years experience & 0.191 & 0.393 & 0.206 & 0.404 \\
\hline tenure 5 & $=1$ if $6-10$ years experience & 0.124 & 0.330 & 0.142 & 0.350 \\
\hline tenure6 & $=1$ if $>10$ years experience & 0.238 & 0.426 & 0.263 & 0.440 \\
\hline bulgarian & $=1$ if Bulgarian ethnicity & 0.901 & 0.298 & 0.896 & 0.305 \\
\hline turk & $=1$ if Turk ethnicity & 0.062 & 0.241 & 0.054 & 0.226 \\
\hline roma & $=1$ if Roma ethnicity & 0.029 & 0.169 & 0.030 & 0.169 \\
\hline school & Total number years in school & 13.056 & 3.420 & 13.875 & 3.424 \\
\hline university & $=1$ if university & 0.167 & 0.374 & 0.256 & 0.437 \\
\hline secondary & $=1$ if secondary technical & 0.620 & 0.486 & 0.532 & 0.499 \\
\hline primary & $=1$ if primary education & 0.154 & 0.361 & 0.105 & 0.307 \\
\hline public & $=1$ if in public sector & 0.306 & 0.461 & 0.390 & 0.488 \\
\hline private & $=1$ if in private sector & 0.603 & 0.490 & 0.540 & 0.499 \\
\hline urban & $=1$ if living in urban & 0.766 & 0.423 & 0.808 & 0.394 \\
\hline rural & $=1$ if living in rural & 0.234 & 0.423 & 0.192 & 0.394 \\
\hline managers & $=1$ if managerial position & 0.042 & 0.200 & 0.026 & 0.160 \\
\hline Sofia_city & $=1$ if living in Sofia & 0.165 & 0.371 & 0.167 & 0.373 \\
\hline Bourgas & $=1$ if living in Bourgas & 0.066 & 0.249 & 0.058 & 0.234 \\
\hline Varna & $=1$ if living in Varna & 0.070 & 0.256 & 0.056 & 0.229 \\
\hline Lovetch & $=1$ if living in Lovetch & 0.022 & 0.148 & 0.021 & 0.144 \\
\hline Montana & $=1$ if living in Montana & 0.014 & 0.117 & 0.022 & 0.146 \\
\hline Plovdiv & $=1$ if living in Plovdiv & 0.087 & 0.282 & 0.103 & 0.304 \\
\hline Rousse & $=1$ if living in Rousse & 0.028 & 0.164 & 0.030 & 0.172 \\
\hline Haskovo & $=1$ if living in Haskovo & 0.029 & 0.167 & 0.030 & 0.169 \\
\hline$N$ & & 1296 & & 1186 & \\
\hline
\end{tabular}


Table 2. Descriptive statistics- Russia, NOBUS 2003

\begin{tabular}{|c|c|c|c|c|c|}
\hline \multicolumn{2}{|l|}{ Russia 2003} & \multicolumn{2}{|c|}{ Males } & \multicolumn{2}{|c|}{ Females } \\
\hline Variable & Description & Mean & Std. Dev. & Mean & Std. Dev. \\
\hline lhwage & Log of hourly wage & 2.862 & 0.812 & 2.605 & 0.730 \\
\hline $\exp$ & Potential experience & 21.587 & 11.463 & 21.488 & 11.002 \\
\hline expsq & Potential experience squared & 597.380 & 519.611 & 582.784 & 484.609 \\
\hline married & $=1$ if married & 0.761 & 0.426 & 0.624 & 0.484 \\
\hline single & $=1$ if single & 0.171 & 0.377 & 0.141 & 0.348 \\
\hline divorced & $=1$ if divorced & 0.067 & 0.251 & 0.234 & 0.424 \\
\hline hours & Number of hours per week & 42.721 & 9.511 & 39.610 & 8.350 \\
\hline tenure 1 & $=1$ if less than 1 year & 0.150 & 0.357 & 0.120 & 0.325 \\
\hline tenure 2 & $=1$ if 1 year but less than 3 years & 0.201 & 0.401 & 0.191 & 0.393 \\
\hline tenure 3 & $=1$ if 3 years but less than 5 years & 0.135 & 0.342 & 0.120 & 0.325 \\
\hline tenure 4 & $=1$ if 5 years but less than 10 years & 0.172 & 0.377 & 0.169 & 0.374 \\
\hline tenure 5 & $=1$ if more than 10 years & 0.342 & 0.474 & 0.400 & 0.490 \\
\hline arrears & $=1$ if arrears effect & 0.189 & 0.392 & 0.138 & 0.345 \\
\hline school & Total number years in school & 11.337 & 2.247 & 11.882 & 2.178 \\
\hline educ2 & $=1$ if Primary general & 0.009 & 0.095 & 0.006 & 0.076 \\
\hline educ3 & $=1$ if Basic general (incomplete secondary) & 0.087 & 0.281 & 0.052 & 0.222 \\
\hline educ4 & $=1$ if Full general (complete secondary) & 0.228 & 0.419 & 0.182 & 0.386 \\
\hline educ5 & $=1$ if Primary vocational (without certificate) & 0.104 & 0.305 & 0.068 & 0.251 \\
\hline educ6 & $=1$ if Primary vocational (with certificate) & 0.047 & 0.211 & 0.032 & 0.175 \\
\hline educ7 & $=1$ if Secondary vocational & 0.307 & 0.461 & 0.378 & 0.485 \\
\hline educ8 & $=1$ if Higher & 0.033 & 0.180 & 0.039 & 0.193 \\
\hline educ9 & $=1$ if University & 0.183 & 0.386 & 0.242 & 0.428 \\
\hline educ10 & $=1$ if Postgraduate & 0.003 & 0.051 & 0.002 & 0.042 \\
\hline settl1 & $=1$ if living in city: 1 million people & 0.105 & 0.306 & 0.109 & 0.311 \\
\hline settl2 & $=1$ if living in town/city 500-999 000 people & 0.087 & 0.282 & 0.092 & 0.289 \\
\hline settl3 & $=1$ if town/city250 -499900 people & 0.137 & 0.344 & 0.149 & 0.356 \\
\hline settl4 & $=1$ if town/city100 -249 900 people & 0.109 & 0.311 & 0.112 & 0.315 \\
\hline settl5 & $=1$ if town/city50 -99900 people & 0.074 & 0.261 & 0.073 & 0.259 \\
\hline settl6 & $=1$ if town/city $20-499000$ people & 0.094 & 0.292 & 0.095 & 0.294 \\
\hline settl7 & $=1$ if town/city 20000 people & 0.143 & 0.350 & 0.139 & 0.346 \\
\hline settl8 & $=1$ if living in village & 0.251 & 0.434 & 0.232 & 0.422 \\
\hline region1 & $=1$ if Central region & 0.214 & 0.410 & 0.222 & 0.415 \\
\hline region 2 & $=1$ if North-West region & 0.139 & 0.346 & 0.140 & 0.347 \\
\hline region3 & $=1$ if Siberia region & 0.131 & 0.337 & 0.131 & 0.338 \\
\hline region4 & $=1$ if South region & 0.130 & 0.336 & 0.127 & 0.333 \\
\hline region5 & $=1$ if Far-East region & 0.134 & 0.341 & 0.131 & 0.337 \\
\hline region6 & $=1$ if Urals & 0.082 & 0.275 & 0.081 & 0.272 \\
\hline region7 & $=1$ if Volga & 0.169 & 0.375 & 0.169 & 0.375 \\
\hline public & $=1$ if in public sector & 0.595 & 0.491 & 0.694 & 0.461 \\
\hline private & $=1$ if in private sector & 0.290 & 0.454 & 0.233 & 0.423 \\
\hline part time & $=1$ if part time & 0.037 & 0.189 & 0.091 & 0.288 \\
\hline health & $=1$ if in very good health & 0.020 & 0.139 & 0.011 & 0.102 \\
\hline managerial & $=1$ if in management position & 0.291 & 0.454 & 0.441 & 0.497 \\
\hline$N$ & & 21874 & & 24318 & \\
\hline
\end{tabular}

Source: Russia, NOBUS data, 2003. 
Table 3. Descriptive statistics- Kazakhstan KHBS, 2003

\begin{tabular}{|c|c|c|c|c|c|}
\hline \multicolumn{2}{|c|}{ Kazakhstan 2003} & \multicolumn{2}{|c|}{ Males } & \multicolumn{2}{|c|}{ Females } \\
\hline Variable & Description & Mean & Std. Dev. & Mean & Std. Dev. \\
\hline lwage & Log of monthly wage & 9.221 & 0.959 & 8.743 & 1.086 \\
\hline $\exp$ & Potential experience & 23.403 & 11.640 & 24.681 & 12.308 \\
\hline expsq & Potential experience squared & 683.169 & 605.763 & 760.625 & 681.546 \\
\hline married & $=1$ if married & 0.794 & 0.404 & 0.582 & 0.493 \\
\hline single & $=1$ if single & 0.175 & 0.380 & 0.142 & 0.349 \\
\hline divorced & $=1$ if divorced & 0.030 & 0.171 & 0.277 & 0.447 \\
\hline school & Total number years in school & 10.358 & 2.742 & 11.155 & 2.878 \\
\hline educ2 & $=1$ if Primary education & 0.008 & 0.089 & 0.012 & 0.110 \\
\hline educ3 & $=1$ if General basic education & 0.060 & 0.238 & 0.051 & 0.221 \\
\hline educ4 & $=1$ if Secondary education & 0.358 & 0.479 & 0.250 & 0.433 \\
\hline educ5 & $=1$ if Vocational education & 0.170 & 0.376 & 0.100 & 0.300 \\
\hline educ6 & $=1$ if College & 0.234 & 0.423 & 0.344 & 0.475 \\
\hline educ7 & $=1$ if University & 0.168 & 0.374 & 0.240 & 0.427 \\
\hline ethnicity1 & $=1$ if Kazakh & 0.560 & 0.496 & 0.472 & 0.499 \\
\hline ethnicity2 & $=1$ if Russian & 0.293 & 0.455 & 0.381 & 0.486 \\
\hline ethnicity 3 & $=1$ if Ukrainian & 0.039 & 0.192 & 0.044 & 0.206 \\
\hline ethnicity4 & $=1$ if Uzbek & 0.026 & 0.159 & 0.017 & 0.129 \\
\hline ethnicity 5 & $=1$ if Tatar & 0.021 & 0.143 & 0.023 & 0.149 \\
\hline public & $=1$ if public sector & 0.279 & 0.449 & 0.406 & 0.491 \\
\hline private & $=1$ if private sector & 0.388 & 0.487 & 0.250 & 0.433 \\
\hline self_empl & $=1$ if self employed & 0.115 & 0.318 & 0.068 & 0.251 \\
\hline regio 1 & $=1$ if Akmolinskay & 0.060 & 0.238 & 0.064 & 0.245 \\
\hline regio2 & $=1$ if Aktubinskaya & 0.043 & 0.203 & 0.047 & 0.211 \\
\hline regio3 & $=1$ if Almatinskaya & 0.100 & 0.300 & 0.075 & 0.263 \\
\hline regio4 & $=1$ if Atirauskaya & 0.028 & 0.164 & 0.026 & 0.160 \\
\hline regio5 & $=1$ if Zapadno-Kazakhstanskaya & 0.037 & 0.188 & 0.042 & 0.201 \\
\hline regio6 & $=1$ if Jambilskaya & 0.071 & 0.257 & 0.057 & 0.231 \\
\hline regio7 & $=1$ if Karagandiskaya & 0.092 & 0.288 & 0.096 & 0.294 \\
\hline regio8 & $=1$ if Kostanayskaya & 0.056 & 0.230 & 0.062 & 0.241 \\
\hline regio9 & $=1$ if Kizilordinskaya & 0.037 & 0.189 & 0.026 & 0.160 \\
\hline regio10 & $=1$ if Magnistaunskaya & 0.027 & 0.163 & 0.025 & 0.155 \\
\hline regio11 & $=1$ if Yujno-Kazakhstanskaya & 0.160 & 0.367 & 0.107 & 0.310 \\
\hline regio12 & $=1$ if Pavlodarskaya & 0.063 & 0.243 & 0.066 & 0.248 \\
\hline regio13 & $=1$ if Severo-Kazakhstanskaya & 0.042 & 0.201 & 0.063 & 0.243 \\
\hline regio14 & $=1$ if Vostochno-Kazakhstanskaya & 0.087 & 0.281 & 0.104 & 0.306 \\
\hline regio 15 & $=1$ if Astana (city) & 0.020 & 0.140 & 0.026 & 0.160 \\
\hline regio16 & $=1$ if Almata (city) & 0.077 & 0.266 & 0.114 & 0.318 \\
\hline setttlem2 & $=1 \mathrm{f}$ in a village & 0.423 & 0.494 & 0.310 & 0.463 \\
\hline setttlem3 & $=1$ if in a large city & 0.282 & 0.450 & 0.357 & 0.479 \\
\hline setttlem4 & $=1$ if in average city & 0.067 & 0.251 & 0.068 & 0.252 \\
\hline setttlem5 & $=1$ if in small city & 0.130 & 0.336 & 0.124 & 0.330 \\
\hline$N$ & & 7868 & & 8507 & \\
\hline
\end{tabular}


Table 4. Descriptive statistics- Serbia, 2003

\begin{tabular}{|c|c|c|c|c|c|}
\hline \multicolumn{2}{|c|}{ Serbia 2003} & \multicolumn{2}{|c|}{ Males } & \multicolumn{2}{|c|}{ Females } \\
\hline Variable & Description & Mean & Std. Dev. & Mean & Std. Dev. \\
\hline lhwage & Log of hourly wage & 4.135 & 0.713 & 3.974 & 0.697 \\
\hline $\exp$ & Potential experience & 25.164 & 12.970 & 24.146 & 12.485 \\
\hline expsq & Potential experience squared & 801.330 & 755.500 & 738.768 & 759.920 \\
\hline hours & Hours worked per month & 164.763 & 67.781 & 155.703 & 57.046 \\
\hline married & $=1$ if married & 0.749 & 0.434 & 0.709 & 0.454 \\
\hline single & $=1$ if single & 0.222 & 0.416 & 0.160 & 0.366 \\
\hline divorced & $=1$ if divorced & 0.029 & 0.169 & 0.131 & 0.338 \\
\hline school & Total number years in school & 11.421 & 2.746 & 11.428 & 3.022 \\
\hline educ1 & $=1$ if Unfinished elementary & 0.041 & 0.198 & 0.044 & 0.205 \\
\hline educ2 & $=1$ if Elementary school & 0.145 & 0.353 & 0.150 & 0.358 \\
\hline educ3 & $=1$ if Vocational school & 0.027 & 0.161 & 0.025 & 0.157 \\
\hline educ4 & $=1$ if Secondary 3 years & 0.287 & 0.453 & 0.169 & 0.375 \\
\hline educ5 & $=1$ if Secondary 4 years & 0.310 & 0.463 & 0.351 & 0.477 \\
\hline educ6 & $=1$ if Gymnasium & 0.025 & 0.155 & 0.041 & 0.198 \\
\hline educ7 & $=1$ if Post secondary & 0.074 & 0.261 & 0.083 & 0.277 \\
\hline educ8 & $=1$ if University & 0.077 & 0.267 & 0.114 & 0.319 \\
\hline educ9 & $=1$ if M.A. degree, specialization & 0.005 & 0.069 & 0.005 & 0.071 \\
\hline urban & $=1$ if in urban & 0.564 & 0.496 & 0.673 & 0.469 \\
\hline rural & $=1$ if in rural area & 0.436 & 0.496 & 0.327 & 0.469 \\
\hline region 1 & $=1$ if living in Belgrade & 0.143 & 0.350 & 0.191 & 0.393 \\
\hline region2 & $=1$ if living in Vojvodina & 0.261 & 0.439 & 0.273 & 0.446 \\
\hline region3 & $=1$ if living in West Serbia & 0.119 & 0.324 & 0.092 & 0.290 \\
\hline region 4 & $=1$ if Šumadija i Pomoravlje & 0.205 & 0.404 & 0.196 & 0.397 \\
\hline region5 & $=1$ if living in East Serbia & 0.104 & 0.306 & 0.098 & 0.297 \\
\hline region6 & $=1$ if living in South-East Serbia & 0.166 & 0.373 & 0.149 & 0.357 \\
\hline private & $=1$ if private & 0.503 & 0.500 & 0.463 & 0.499 \\
\hline state & $=1$ if state & 0.457 & 0.498 & 0.506 & 0.500 \\
\hline$N$ & & 1466 & & 984 & \\
\hline
\end{tabular}


Table 5. Return to education by Quantiles, Males, Bulgaria, 2003

\begin{tabular}{|c|c|c|c|c|c|}
\hline MALES & $\theta=0.10$ & $\theta=0.25$ & $\theta=0.50$ & $\theta=0.75$ & $\theta=0.90$ \\
\hline \multicolumn{6}{|c|}{ (1) Unadjusted QR estimates } \\
\hline \multirow[t]{2}{*}{ Schooling } & $0.0391^{* * *}$ & $0.0408^{* * *}$ & $0.0478^{* * *}$ & $0.0531^{* * *}$ & $0.0600^{* * *}$ \\
\hline & $(0.0060)$ & $(0.0067)$ & $(0.0063)$ & $(0.0078)$ & $(0.0081)$ \\
\hline Pseudo $R^{2}$ & 0.1204 & 0.1586 & 0.1818 & 0.2057 & 0.2012 \\
\hline$N$ & 1298 & 1298 & 1298 & 1298 & 1298 \\
\hline \multicolumn{6}{|c|}{ (2) $Q R$ with sample selection } \\
\hline \multirow[t]{2}{*}{ Schooling } & $0.0328^{* * *}$ & $0.0287^{* * *}$ & $0.0419^{* * *}$ & $0.0492^{* * *}$ & $0.0578^{* * *}$ \\
\hline & $(0.0079)$ & $(0.0079)$ & $(0.0089)$ & $(0.0097)$ & $(0.0092)$ \\
\hline \multirow[t]{2}{*}{$\left(z^{\prime} \gamma\right)$} & 1.1023 & 1.5857 & 0.9804 & 0.4336 & -0.8545 \\
\hline & $(0.8580)$ & $(0.9321)$ & $(1.0629)$ & $(1.1166)$ & $(1.1040)$ \\
\hline \multirow[t]{2}{*}{$\left(z^{\prime} \gamma\right)^{2}$} & -0.2056 & -0.2253 & -0.1670 & -0.0265 & 0.2463 \\
\hline & $(0.1946)$ & $(0.2109)$ & $(0.2439)$ & $(0.2631)$ & $(0.2706)$ \\
\hline Pseudo $R^{2}$ & 0.1224 & 0.1627 & 0.1828 & 0.2065 & 0.2030 \\
\hline$N$ & 1296 & 1296 & 1296 & 1296 & 1296 \\
\hline \multicolumn{6}{|c|}{ (3)Endogeneity adjusted QR estimates } \\
\hline \multirow[t]{2}{*}{ Schooling } & $0.0455^{* *}$ & $0.0388^{* *}$ & $0.0376^{* *}$ & $0.0693^{* * *}$ & $0.0607^{*}$ \\
\hline & $(0.0225)$ & $(0.0123)$ & $(0.0187)$ & $(0.0174)$ & $(0.0248)$ \\
\hline Pseudo $R^{2}$ & 0.0941 & 0.1156 & 0.1356 & 0.1599 & 0.1524 \\
\hline$N$ & 1060 & 1060 & 1060 & 1060 & 1060 \\
\hline
\end{tabular}

Notes: (i) Bootstrapped errors in parentheses ${ }^{*} p<0.05,{ }^{* *} p<0.01,{ }^{* * *} p<0.001$; (ii) The estimated adjusted and unadjusted QR includes control variables for potential experience and exp squared, job tenure dummies, marital status dummies, Bulgarian ethnicity, urban settlement, public sector, good health status and being with managerial duties. The full results are available on request. (iii) The F-test for the equality of unadjusted QR coefficients at $90^{\text {th }}$ and $10^{\text {th }} \mathrm{F}(1,1284)=4.16^{* * * *}$, and the F-test for the equality of all quantiles $\mathrm{F}(4,1284)=1.02^{* * *}$ hence we reject the assumption that unadjusted QR estimates are equal based on their F-statistics and $p$-values from equality testing. (iv) Durbin-WuHausman $(\mathrm{DWH}) \boldsymbol{p}$-value $=0.18282$ and we do not reject the null hypothesis.

Table 6. Return to education by Quantiles, Females, Bulgaria, 2003

\begin{tabular}{|c|c|c|c|c|c|}
\hline FEMALES & $\theta=0.10$ & $\theta=0.25$ & $\theta=0.50$ & $\theta=0.75$ & $\theta=0.90$ \\
\hline \multicolumn{6}{|c|}{ (1) Unadjusted QR estimates } \\
\hline \multirow[t]{2}{*}{ Schooling } & $0.0498^{* * * *}$ & $0.0516^{* * *}$ & $0.0631^{* * *}$ & $0.0660^{* * *}$ & $0.0736^{* * *}$ \\
\hline & $(0.0060)$ & $(0.0042)$ & $(0.0049)$ & $(0.0058)$ & $(0.0097)$ \\
\hline Pseudo $R^{2}$ & 0.1531 & 0.1666 & 0.1911 & 0.1958 & 0.1959 \\
\hline$N$ & 1187 & 1187 & 1187 & 1187 & 1187 \\
\hline \multicolumn{6}{|c|}{ (2) $Q R$ with sample selection } \\
\hline \multirow[t]{2}{*}{ Schooling } & $0.0683^{* * *}$ & $0.0488^{* * *}$ & $0.0684^{* * *}$ & $0.0706^{* * *}$ & $0.0816^{* * *}$ \\
\hline & $(0.0153)$ & $(0.0100)$ & $(0.0136)$ & $(0.0143)$ & $(0.0244)$ \\
\hline \multirow[t]{2}{*}{$\left(z^{\prime} \gamma\right)$} & -0.0800 & 0.2785 & -0.2664 & -0.3003 & -0.4321 \\
\hline & $(0.9932)$ & $(0.6120)$ & $(0.8047)$ & $(0.8328)$ & $(1.4145)$ \\
\hline \multirow[t]{2}{*}{$\left(z^{\prime} \gamma\right)^{2}$} & -0.1840 & -0.0425 & 0.0064 & 0.0338 & 0.0394 \\
\hline & $(0.2209)$ & $(0.1354)$ & $(0.1698)$ & $(0.1722)$ & $(0.2876)$ \\
\hline Pseudo $R^{2}$ & 0.1556 & 0.1667 & 0.1913 & 0.1960 & 0.1963 \\
\hline$N$ & 1186 & 1186 & 1186 & 1186 & 1186 \\
\hline \multicolumn{6}{|c|}{ (2)Endogeneity adjusted $Q R$ estimates } \\
\hline \multirow[t]{2}{*}{ Schooling } & $0.0645^{* * *}$ & $0.0615^{* * *}$ & $0.0718^{* * *}$ & $0.0954^{* * *}$ & $0.1515^{* * *}$ \\
\hline & $(0.0123)$ & $(0.0072)$ & $(0.0110)$ & $(0.0174)$ & $(0.0290)$ \\
\hline Pseudo $R^{2}$ & 0.2128 & 0.2326 & 0.2612 & 0.2500 & 0.2785 \\
\hline$N$ & 548 & 548 & 548 & 548 & 548 \\
\hline
\end{tabular}

Notes: (i) Bootstrapped errors in parentheses ${ }^{*} p<0.05,{ }^{* *} p<0.01,{ }^{* * *} p<0.001 ;$; (ii) The estimated adjusted and unadjusted QR includes control variables for potential experience and exp squared, job tenure dummies, marital status dummies, Bulgarian ethnicity, urban settlement, public sector, good health status and being with managerial duties. The full results are available on request. (iii) The $F$-test for the equality of unadjusted QR coefficients at $90^{\text {th }}$ and $10^{\text {th }}$ is $F(1,1173)=4.07^{* *}$, and the F-test for the equality of all quantiles $F(4,1173)=$ $1.71^{* *}$; (iv) Durbin-Wu-Hausman (DWH) $p$-value $=0.00011$ and we reject the null hypothesis. 
Table 7. Return to education by Quantiles, Russia, Males, 2003

\begin{tabular}{|c|c|c|c|c|c|}
\hline MALES & $\theta=0.10$ & $\theta=0.25$ & $\theta=0.50$ & $\theta=0.75$ & $\theta=0.90$ \\
\hline \multicolumn{6}{|c|}{ (1) Unadjusted OR estimates } \\
\hline \multirow[t]{2}{*}{ Schooling } & $0.0930^{* * * *}$ & $0.0787^{* * *}$ & $0.0673^{* * *}$ & $0.0624^{* * *}$ & $0.0593^{* * *}$ \\
\hline & $(0.0048)$ & $(0.0036)$ & $(0.0028)$ & $(0.0031)$ & $(0.0038)$ \\
\hline Pseudo $R^{2}$ & 0.1630 & 0.1505 & 0.1459 & 0.1406 & 0.1461 \\
\hline$N$ & 21373 & 21373 & 21373 & 21373 & 21373 \\
\hline \multicolumn{6}{|c|}{ (2) $Q R$ with sample selection } \\
\hline \multirow[t]{2}{*}{ Schooling } & $0.1198^{* * * *}$ & $0.0884^{* * * *}$ & $0.0742^{* * *}$ & $0.0654^{* * *}$ & $0.0599^{* * *}$ \\
\hline & $(0.0069)$ & $(0.0049)$ & $(0.0037)$ & $(0.0045)$ & $(0.0051)$ \\
\hline \multirow[t]{2}{*}{$\left(z^{\prime} \gamma\right)$} & $1.3263^{* * *}$ & $1.5846^{* * *}$ & $1.2291^{* * *}$ & $0.8826^{* * *}$ & $0.9762^{* * * *}$ \\
\hline & $(0.2459)$ & $(0.1731)$ & $(0.1328)$ & $(0.1604)$ & $(0.1782)$ \\
\hline \multirow[t]{2}{*}{$\left(z^{\prime} \gamma\right)^{2}$} & $-0.2627^{* * *}$ & $-0.2757^{\text {**** }}$ & $-0.2064^{* * * *}$ & $-0.1514^{* * *}$ & $-0.1503^{\text {**** }}$ \\
\hline & $(0.0352)$ & $(0.0251)$ & $(0.0196)$ & $(0.0240)$ & $(0.0267)$ \\
\hline Pseudo $R^{2}$ & 0.1637 & 0.1572 & 0.1501 & 0.1472 & 0.1510 \\
\hline$N$ & 19486 & 19486 & 19486 & 19486 & 19486 \\
\hline \multicolumn{6}{|c|}{ (3) Endogeneity adjusted QR estimates } \\
\hline \multirow[t]{2}{*}{ Schooling } & $0.0931^{* * *}$ & $0.0821^{* * *}$ & $0.0781^{* * *}$ & $0.0488^{* * *}$ & -0.0008 \\
\hline & $(0.0235)$ & $(0.0129)$ & $(0.0079)$ & $(0.0140)$ & $(0.0132)$ \\
\hline Pseudo $R^{2}$ & 0.1430 & 0.1308 & 0.1258 & 0.1270 & 0.1327 \\
\hline$N$ & 7442 & 7442 & 7442 & 7442 & 7442 \\
\hline
\end{tabular}

Notes: (i) Bootstrapped errors in parentheses ${ }^{*} p<0.05,{ }^{* *} p<0.01,{ }^{* * *} p<0.001$; (ii) The estimated adjusted and unadjusted QR includes control variables for potential experience and experience squared, dummies for tenure, regional dummies, arrears effect, part time work status, good health status, government sector and being with managerial responsibilities. The full results are available on request; (iii) The $F$-test for the equality of the unadjusted $\mathrm{QR}$ coefficients at $90^{\text {th }}$ and $10^{\text {th }}$ is $\mathrm{F}(1,21352)=30.87^{* * * *}$, and the $F$-test for the equality of all quantiles $\mathrm{F}(4,21352)=8.69^{* * * *}$ (iv) The DWH test is 2.8023 and p-value 0.0941 and we do not reject the null hypothesis.

Table 8. Return to education by Quantiles, Russia, Females, 2003

\begin{tabular}{|c|c|c|c|c|c|}
\hline FEMALES & $\theta=0.10$ & $\theta=0.25$ & $\theta=0.50$ & $\theta=0.75$ & $\theta=0.90$ \\
\hline \multicolumn{6}{|c|}{ (1) Unadjusted $Q R$ estimates } \\
\hline \multirow[t]{2}{*}{ Schooling } & $0.0896^{* * * *}$ & $0.0895^{* * *}$ & $0.0831^{* * *}$ & $0.0724^{* * *}$ & $0.0667^{* * *}$ \\
\hline & $(0.0036)$ & $(0.0025)$ & $(0.0026)$ & $(0.0027)$ & $(0.0040)$ \\
\hline Pseudo $R^{2}$ & 0.1517 & 0.1607 & 0.1582 & 0.1525 & 0.1473 \\
\hline$N$ & 23965 & 23965 & 23965 & 23965 & 23965 \\
\hline \multicolumn{6}{|c|}{ (2) $Q R$ with sample selection } \\
\hline \multirow[t]{2}{*}{ Schooling } & $0.0599^{* * *}$ & $0.0628^{* * *}$ & $0.0553^{* * *}$ & $0.0481^{* * *}$ & $0.0445^{* * *}$ \\
\hline & $(0.0087)$ & $(0.0069)$ & $(0.0069)$ & $(0.0080)$ & $(0.0098)$ \\
\hline \multirow[t]{2}{*}{$\left(z^{\prime} \gamma\right)$} & $0.4382^{* *}$ & $0.4723^{* * * *}$ & $0.5886^{* * * *}$ & $0.4677^{* *}$ & $0.4676^{* *}$ \\
\hline & $(0.1700)$ & $(0.1346)$ & $(0.1373)$ & $(0.1623)$ & $(0.1990)$ \\
\hline \multirow[t]{2}{*}{$\left(z^{\prime} \gamma\right)^{2}$} & -0.0217 & $-0.0331^{*}$ & $-0.0515^{* *}$ & $-0.0359^{*}$ & -0.0392 \\
\hline & $(0.0244)$ & $(0.0195)$ & $(0.0199)$ & $(0.0235)$ & $(0.0287)$ \\
\hline Pseudo $R^{2}$ & 0.1525 & 0.1608 & 0.1588 & 0.1524 & 0.1474 \\
\hline$N$ & 23711 & 23711 & 23711 & 23711 & 23711 \\
\hline \multicolumn{6}{|c|}{ (3) Endogeneity adjusted QR estimates } \\
\hline \multirow[t]{2}{*}{ Schooling } & $0.0960^{* * * *}$ & $0.0854^{* * * *}$ & $0.0963^{* * *}$ & $0.1310^{* * *}$ & $0.0905^{* *}$ \\
\hline & $(0.0181)$ & $(0.0123)$ & $(0.0093)$ & $(0.0240)$ & $(0.0300)$ \\
\hline Pseudo $R^{2}$ & 0.1616 & 0.1774 & 0.1771 & 0.1791 & 0.1731 \\
\hline$N$ & 6592 & 6592 & 6592 & 6592 & 6592 \\
\hline
\end{tabular}

Notes: (i) Bootstrapped errors in parentheses ${ }^{*} p<0.05,{ }^{* *} p<0.01,{ }^{* * *} p<0.001$; (ii) The estimated adjusted and unadjusted QR includes control variables for potential experience and experience squared, dummies for tenure, regional dummies, arrears effect, part time work status, good health status, government sector and being with managerial responsibilities. The full results are available on request; (iii) The F-test for the equality of the unadjusted QR coefficients at $90^{\text {th }}$ and $10^{\text {th }}$ is $\mathrm{F}(1,23944)=21.27^{* * * *}$, and the $F$-test for the equality of all quantiles is $\mathrm{F}(4,23944)=8.19^{* * * *}$; (iv) The DWH test $(27.37$ and p-value 0.000$)$ shows strong rejection of the null hypothesis that female education variable is exogenous. We conclude that it is endogenous and that there is a difference between endogeneity adjusted and unadjusted QR estimates. 
Table 9. Return to education by Quantiles, Kazakhstan, Males, 2003

\begin{tabular}{|c|c|c|c|c|c|}
\hline MALES & $\theta=0.10$ & $\theta=0.25$ & $\theta=0.50$ & $\theta=0.75$ & $\theta=0.90$ \\
\hline \multicolumn{6}{|c|}{ (1) Unadjusted QR estimates } \\
\hline \multirow[t]{2}{*}{ Schooling } & $0.0240^{* * *}$ & $0.0444^{* * *}$ & $0.0472^{* * *}$ & $0.0450^{* * *}$ & $0.0483^{* * *}$ \\
\hline & $(0.0086)$ & $(0.0045)$ & $(0.0038)$ & $(0.0040)$ & $(0.0041)$ \\
\hline Pseudo $R^{2}$ & 0.2566 & 0.2109 & 0.1913 & 0.1841 & 0.1859 \\
\hline$N$ & 7833 & 7833 & 7833 & 7833 & 7833 \\
\hline \multicolumn{6}{|c|}{ (2) $Q R$ with sample selection } \\
\hline \multirow[t]{2}{*}{ Schooling } & 0.0082 & 0.0514 & -0.0180 & -0.0335 & 0.0113 \\
\hline & $(0.0682)$ & $(0.0419)$ & $(0.0284)$ & $(0.0291)$ & $(0.0381)$ \\
\hline \multirow{2}{*}{$\left(z^{\prime} \gamma\right)$} & 1.3619 & -0.1627 & $4.1319^{*}$ & $5.1527^{* * *}$ & 2.5732 \\
\hline & $(4.1489)$ & $(2.5670)$ & $(1.7398)$ & $(1.7814)$ & $(2.3270)$ \\
\hline \multirow[t]{2}{*}{$\left(z^{\prime} \gamma\right)^{2}$} & $-0.0562^{* * * *}$ & $-0.0724^{* * * *}$ & $-0.0724^{* * *}$ & $-0.0709^{* * *}$ & $-0.0577^{* * *}$ \\
\hline & $(0.0122)$ & $(0.0081)$ & $(0.0060)$ & $(0.0063)$ & $(0.0083)$ \\
\hline Pseudo $R^{2}$ & 0.2584 & 0.2165 & 0.1997 & 0.1920 & 0.1925 \\
\hline$N$ & 7833 & 7833 & 7833 & 7833 & 7833 \\
\hline \multicolumn{6}{|c|}{ (3) Endogeneity adjusted QR estimates } \\
\hline \multirow[t]{2}{*}{ Schooling } & $0.0775^{* * *}$ & $0.0486^{* * *}$ & $0.0386^{* *}$ & $0.0557^{* * *}$ & $0.0872^{* * *}$ \\
\hline & $(0.0176)$ & $(0.0129)$ & $(0.0097)$ & $(0.0100)$ & $(0.0173)$ \\
\hline Pseudo $R^{2}$ & 0.2933 & 0.2309 & 0.2089 & 0.1973 & 0.2025 \\
\hline$N$ & 5371 & 5371 & 5371 & 5371 & 5371 \\
\hline
\end{tabular}

Notes: (i) Bootstrapped errors in parentheses ${ }^{*} p<0.05,{ }^{* *} p<0.01,{ }^{* * *} p<0.001(\mathrm{ii})$ The estimated adjusted and unadjusted QR includes control variables for potential experience and experience squared, regional variables, marital status dummies, Kazakh ethnicity, good health status, public sector and self-employment status. The full results are available on request; (iii) The F-test for the equality of unadjusted QR coefficients at $90^{\text {th }}$ and $10^{\text {th }}$ is $\mathrm{F}$ $(1,7806)=7.47^{* * *}$ and the F-test for the equality of all quantiles $\mathrm{F}(4,7806)=2.50^{* * *}$ (iv) The DWH test (3.28694, p-value 0.06983) and we do not reject the hull hypothesis.

Table 10. Return to education by Quantiles, Kazakhstan, Females, 2003

\begin{tabular}{|c|c|c|c|c|c|}
\hline FEMALES & $\theta=0.10$ & $\theta=0.25$ & $\theta=0.50$ & $\theta=0.75$ & $\theta=0.90$ \\
\hline \multicolumn{6}{|c|}{ (1) Unadjusted QR estimates } \\
\hline \multirow[t]{2}{*}{ Schooling } & $0.0121^{* * *}$ & $0.0416^{* * *}$ & $0.0549^{* * *}$ & $0.0582^{* * *}$ & $0.0638^{* * *}$ \\
\hline & $(0.0017)$ & $(0.0051)$ & $(0.0034)$ & $(0.0041)$ & $(0.0043)$ \\
\hline Pseudo $R^{2}$ & 0.2756 & 0.3077 & 0.2283 & 0.1842 & 0.1612 \\
\hline$N$ & 8482 & 8482 & 8482 & 8482 & 8482 \\
\hline \multicolumn{6}{|c|}{ (2) $Q R$ with sample selection } \\
\hline \multirow[t]{2}{*}{ Schooling } & $0.0154^{* * *}$ & $0.0347^{* * *}$ & $0.0484^{* * *}$ & $0.0570^{* * *}$ & $0.0598^{* * *}$ \\
\hline & $(0.0020)$ & $(0.0054)$ & $(0.0044)$ & $(0.0034)$ & $(0.0052)$ \\
\hline \multirow[t]{2}{*}{$\left(z^{\prime} \gamma\right)$} & $0.0790^{*}$ & $0.3661^{* * * *}$ & $0.4372^{* * *}$ & $0.4465^{* * *}$ & $0.4037^{* * * *}$ \\
\hline & $(0.0352)$ & $(0.0972)$ & $(0.0819)$ & $(0.0627)$ & $(0.0952)$ \\
\hline \multirow[t]{2}{*}{$\left(z^{\prime} \gamma\right)^{2}$} & $0.0261^{\text {**** }}$ & $0.0236^{* * * *}$ & $-0.0290^{* * *}$ & $-0.0393^{* * *}$ & $-0.0409^{* * * *}$ \\
\hline & $(0.0029)$ & $(0.0061)$ & $(0.0056)$ & $(0.0050)$ & $(0.0082)$ \\
\hline Pseudo $R^{2}$ & 0.2785 & 0.3098 & 0.2309 & 0.1913 & 0.1711 \\
\hline$N$ & 8482 & 8482 & 8482 & 8482 & 8482 \\
\hline \multicolumn{6}{|c|}{ (3) Endogeneity adjusted QR estimates } \\
\hline \multirow[t]{2}{*}{ Schooling } & $0.0206^{* * *}$ & $0.0444^{* * *}$ & $0.0558^{* * *}$ & $0.1263^{* * *}$ & $0.1420^{* * *}$ \\
\hline & $(0.0056)$ & $(0.0131)$ & $(0.0089)$ & $(0.0105)$ & $(0.0185)$ \\
\hline Pseudo $R^{2}$ & 0.2746 & 0.3528 & 0.2683 & 0.2264 & 01932 \\
\hline$N$ & 4773 & 4773 & 4773 & 4773 & 4773 \\
\hline
\end{tabular}

Notes: (i) Bootstrapped errors in parentheses ${ }^{*} p<0.05,{ }^{* *} p<0.01,{ }^{* * *} p<0.001$; (ii) The estimated adjusted and unadjusted QR includes control variables for potential experience and experience squared, regional variables, marital status dummies, Kazakh ethnicity, good health status, public sector and self-employment status. The full results are available on request; (ii) The F-test for the equality of unadjusted QR coefficients at $90^{\text {th }}$ and $10^{\text {th }}$ is $F(1$, $8455)=111.89^{* * * *}$ and the F-test for the equality of all quantiles $\mathrm{F}(1,8455)=38.21^{* * * *}$ (iv) The DWH test (8.46329, p-value 0.00062) results leads to rejection of the null hypotheses and we conclude that endogeneity is an issue in female specification. 
Table 11. Return to education by Quantiles, Serbia, Males, 2003

\begin{tabular}{llllll}
\hline MALES & $\theta=0.10$ & $\theta=0.25$ & $\theta=0.50$ & $\theta=0.75$ & $\theta=0.90$ \\
\hline $\begin{array}{llllll}(1) \\
\text { Schooling }\end{array}$ & $0.0512^{* *}$ & $0.0558^{* * *}$ & $0.0624^{* * *}$ & $0.0541^{* * *}$ & $0.0598^{*}$ \\
& $(0.0157)$ & $(0.0079)$ & $(0.0064)$ & $(0.0097)$ & $(0.0242)$ \\
Pseudo $R^{2}$ & 0.1087 & 0.1071 & 0.0836 & 0.0739 & 0.0690 \\
$N$ & 1466 & 1466 & 1466 & 1466 & 1466 \\
$(2)$ QR with sample selection & & & & \\
Schooling & $0.0769^{*}$ & $0.0792^{*}$ & $0.0706^{*}$ & $0.0678^{*}$ & -0.0207 \\
& $(0.0327)$ & $(0.0315)$ & $(0.0274)$ & $(0.0312)$ & $(0.0644)$ \\
$\left(z^{\prime} \gamma\right)$ & -0.3742 & -0.4262 & -0.2652 & -0.1332 & 0.6282 \\
& $(0.3219)$ & $(0.2530)$ & $(0.2133)$ & $(0.2411)$ & $(0.4705)$ \\
$\left(z^{\prime} \gamma\right)^{2}$ & 0.0497 & $0.0527^{*}$ & 0.0291 & 0.0188 & 0.0052 \\
& $(0.0438)$ & $(0.0268)$ & $(0.0244)$ & $(0.0285)$ & $(0.0488)$ \\
Pseudo $R^{2}$ & 0.0980 & 0.0936 & 0.0809 & 0.1000 & 0.1220 \\
$N$ & 455 & 455 & 455 & 455 & 455 \\
$(3)$ Endogeneity adjusted $Q R$ estimates & & & \\
Schooling & 0.0387 & 0.0560 & $0.0487^{*}$ & 0.0781 & $0.0969^{* *}$ \\
& $(0.0377)$ & $(0.0251)$ & $(0.0242)$ & $(0.0404)$ & $(0.0312)$ \\
Pseudo $R^{2}$ & 0.1008 & 0.1153 & 0.1066 & 0.1044 & 0.1081 \\
$N$ & 1394 & 1394 & 1394 & 1394 & 1394 \\
\hline
\end{tabular}

Notes: (i) Bootstrapped errors in parentheses ${ }^{*} p<0.05,{ }^{* *} p<0.01,{ }^{* * *} p<0.001$; (ii) The estimated adjusted and unadjusted QR includes control variables for potential experience and exp squared, regional variables, marital status, rural residence, public sector and working as a managerial responsibilities. The full results are available on request; (iii) The F-test for the equality of unadjusted QR coefficients at $90^{\text {th }}$ and $10^{\text {th }}$ is $\mathrm{F}$ ( $1,1451)=0.12$, and the F-test for the equality of all quantiles is $F(4,1451)=0.21$. (iv) The DWH test (0.00013, p-value 0.99102);

Table 12. Estimated Return to education, Female, Serbia, 2003

\begin{tabular}{|c|c|c|c|c|c|}
\hline FEMALES & $\theta=0.10$ & $\theta=0.25$ & $\theta=0.50$ & $\theta=0.75$ & $\theta=0.90$ \\
\hline \multicolumn{6}{|c|}{ (1) Unadjusted $Q R$ estimates } \\
\hline \multirow[t]{2}{*}{ Schooling } & $0.0715^{* * *}$ & $0.0853^{* * *}$ & $0.1049^{* * *}$ & $0.1034^{* * *}$ & $0.1310^{* * *}$ \\
\hline & $(0.0146)$ & $(0.0138)$ & $(0.0110)$ & $(0.0123)$ & $(0.0222)$ \\
\hline Pseudo $R^{2}$ & 0.1788 & 0.1654 & 0.1539 & 0.1285 & 0.1345 \\
\hline$N$ & 984 & 984 & 984 & 984 & 984 \\
\hline \multicolumn{6}{|c|}{ (2) $Q R$ with sample selection } \\
\hline \multirow[t]{2}{*}{ Schooling } & 0.0072 & $0.1016^{* *}$ & $0.0693^{* * *}$ & $0.1203^{* * *}$ & $0.1697^{* *}$ \\
\hline & $(0.1208)$ & $(0.0358)$ & $(0.0194)$ & $(0.0174)$ & $(0.0597)$ \\
\hline \multirow[t]{2}{*}{$\left(z^{\prime} \gamma\right)$} & -0.3765 & -0.2274 & -0.2356 & 0.0393 & -0.0553 \\
\hline & $(1.0589)$ & $(0.4817)$ & $(0.2544)$ & $(0.2048)$ & (0.7899) \\
\hline \multirow[t]{2}{*}{$\left(z^{\prime} \gamma\right)^{2}$} & 0.0270 & 0.0618 & 0.0372 & -0.0025 & 0.0362 \\
\hline & $(0.3098)$ & $(0.0983)$ & $(0.0553)$ & $(0.0492)$ & $(0.1590)$ \\
\hline Pseudo $R^{2}$ & 0.1852 & 0.1727 & 0.1586 & 0.2446 & 0.2933 \\
\hline$N$ & 136 & 136 & 136 & 136 & 136 \\
\hline \multicolumn{6}{|c|}{ (3) Endogeneity adjusted QR estimates } \\
\hline \multirow[t]{2}{*}{ Schooling } & $0.0360^{* *}$ & $0.0502^{* *}$ & $0.1568^{* * *}$ & $0.1042^{* * *}$ & $0.1162^{* * *}$ \\
\hline & $(0.0449)$ & $(0.0338)$ & $(0.0233)$ & $(0.0118)$ & $(0.0230)$ \\
\hline Pseudo $R^{2}$ & 0.1466 & 0.1629 & 0.1844 & 0.1708 & 0.1603 \\
\hline$N$ & 925 & 925 & 925 & 925 & 925 \\
\hline
\end{tabular}

Notes: (i) Bootstrapped errors in parentheses ${ }^{*} p<0.05,{ }^{* *} p<0.01,{ }^{* * *} p<0.001$; (ii) The estimated adjusted and unadjusted QR includes control variables for potential experience and exp squared, regional variables, marital status, rural residence, public sector and working as a managerial responsibilities. The full results are available on request; (iii) The F-test for the equality of coefficients at $90^{\text {th }}$ and $10^{\text {th }}$ is $\mathrm{F}$ $(1,969)=5.15^{* * *}$, and the F-test for the equality of all quantiles is $\mathrm{F}(4,969)=1.78^{*}$ (iv) The DWH test (6.69350, p-value 0.00968), we reject the null at conventional level of significance. 
Figure 1. Return to education by Quantiles, Bulgaria 2003
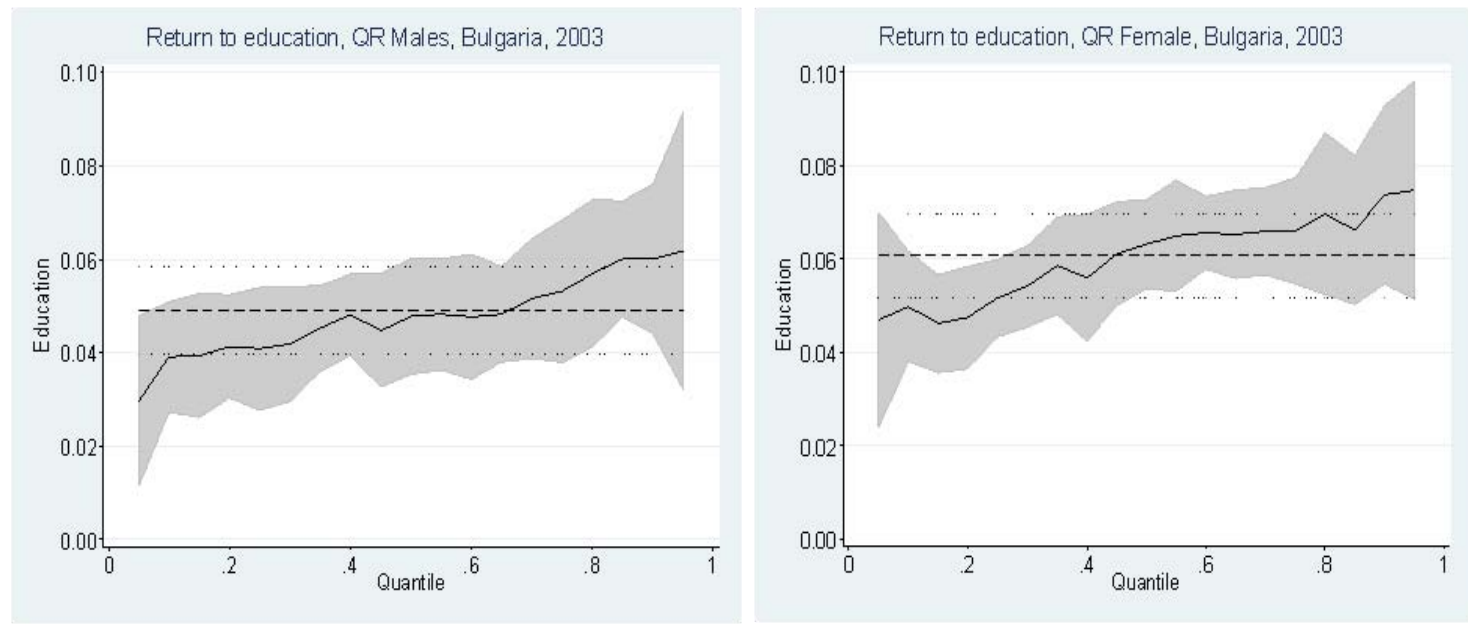

Notes: Bulgaria, 2003. The $\mathrm{y}$-axis measures the return to education coefficients; the $\mathrm{x}$-axis depicts the selected quantiles of the conditional wage distribution for male and females. The horizontal line plots the OLS estimate and its 95\% confidence interval. The Breusch-Pagan (B-P) (aka Cook-Weisberg) test for heteroskedasticity leads us to reject the null hypothesis of homoskedasticity: B-P test in male OLS: 32.10, p-value (0.0023); female OLS B-P test statistics: 141.92, p-value: (0.0000). We also perform the overall joint IM test and our p-values results lead the null hypotheses of homoskedasticity and symmetry to be rejected for male and female.

Figure 2. Return to education by Quantiles, Russia 2003
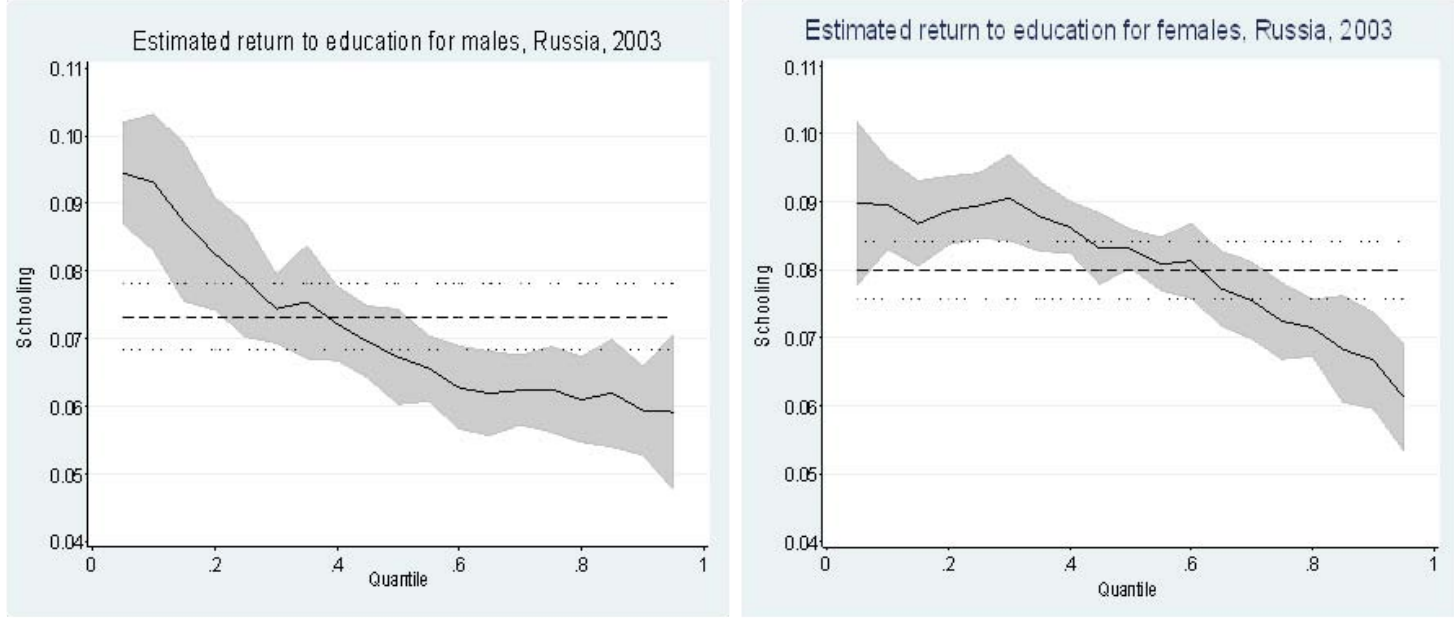

Notes: Russia, 2003. The y-axis measures the return to education coefficients; the $\mathrm{x}$-axis depicts the selected quantiles of the conditional wage distribution for male and females. The horizontal line plots the OLS estimate and its $95 \%$ confidence interval. Breusch-Pagan (Cook-Weisberg) test strongly suggest that the errors are heteroskedastic because the B-P test in male OLS: 62.48, $p$-value $=0.0000$; female OLS B-P test statistics is 15.60 , $p$-value $=0.0000$; the overall joint IM test reject the model assumption that $y \sim N\left(x^{\prime} \beta, \sigma^{2} I\right)$ and we reject all three assumptions of homoskedasticity, symmetry and normal kurtosis in male and female specifications. 
Figure 3. Return to education by Quantiles, Kazakhstan 2003
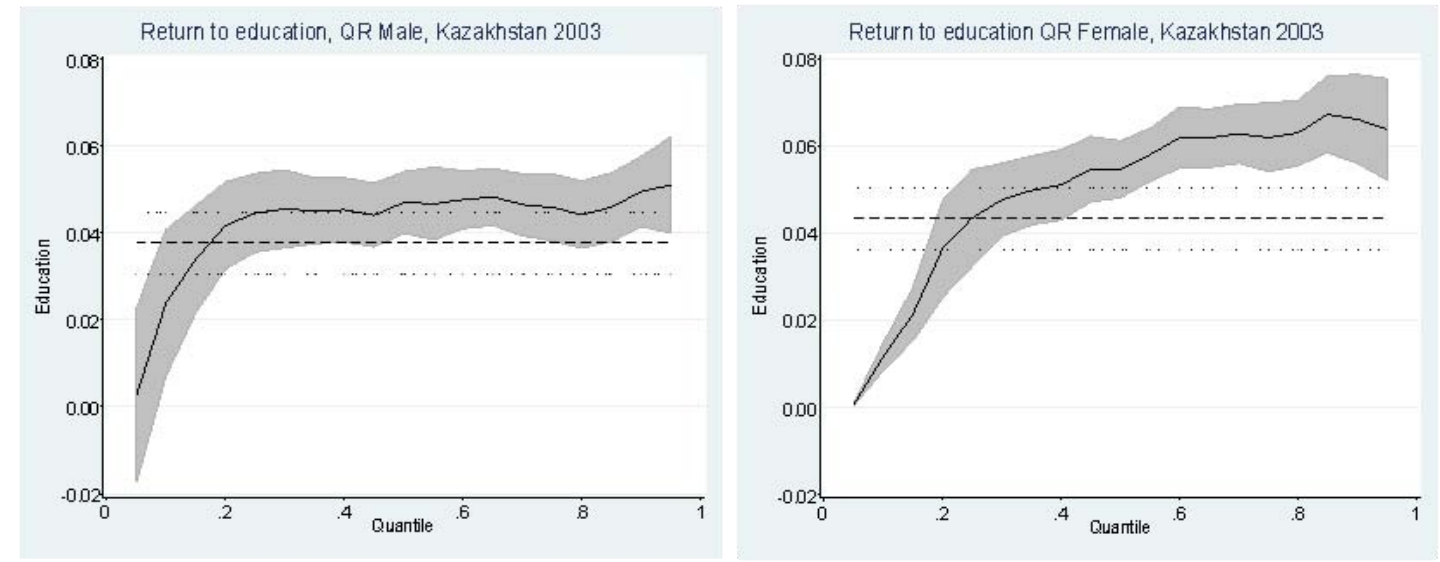

Notes: Kazakhstan 2003. The y-axis measures the return to education coefficients; the $\mathrm{x}$-axis depicts the selected quantiles of the conditional wage distribution for male and females. The horizontal lines are the least squares (mean) returns (OLS) and its 95\% confidence intervals. The Breusch-Pagan (aka Cook-Weisberg) test for heteroskedasticity that leads us to reject the null hypothesis of homoskedasticity: B-P test in Male OLS: 881.68, p-value 0.0000; female OLS B-P test statistics: 1137.85 , p-value: 0.0000 . We also perform the overall joint IM test and our p-values results lead the null hypotheses of homoskedasticity and symmetry to be rejected for male and female.

Figure 4. Return to education by Quantiles, Serbia 2003
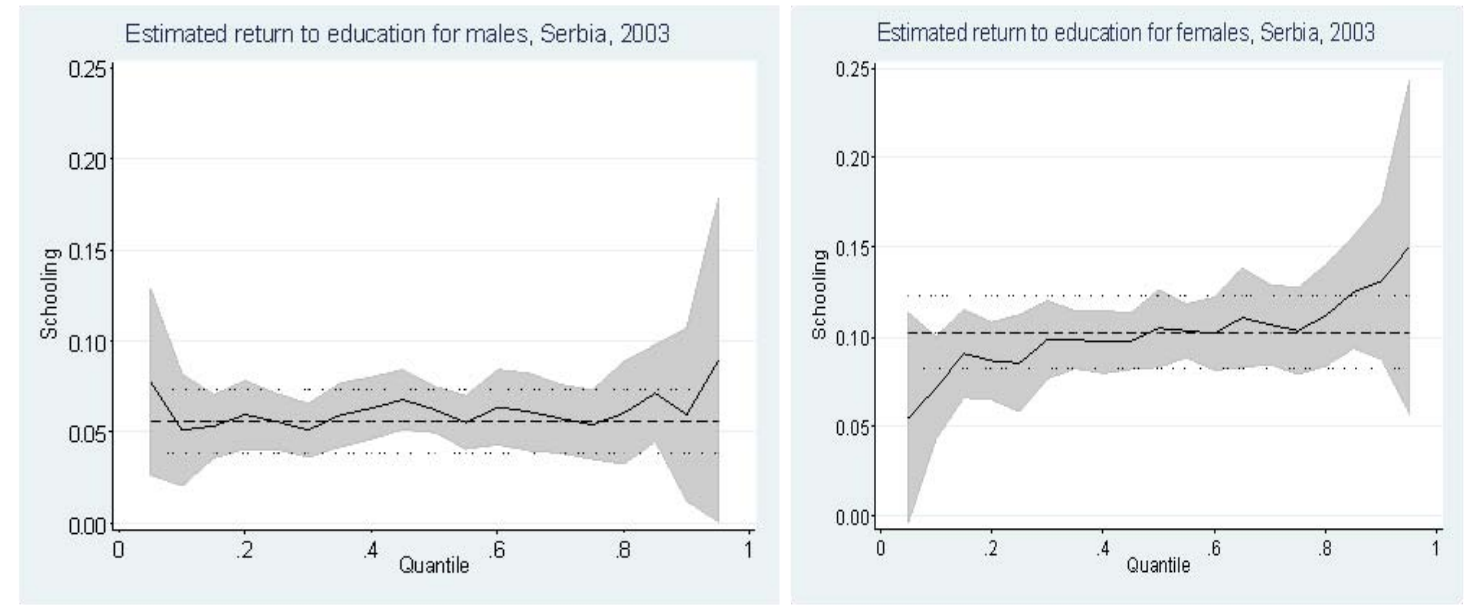

Notes: Serbia 2003. The y-axis measures the return to education coefficients; the $\mathrm{x}$-axis depicts the selected quantiles of the conditional wage distribution for male and females. The horizontal lines plot the OLS estimate and its $95 \%$ confidence interval. 